spliceosome to perform as a quick-acting valve to switch on the production of certain proteins.

eLife 2, e00780 (2013)

\section{SOCIAL BIOLOGY}

\section{Insects show savvy mob mentality}

Among social insects, individuals excel at easy decisions and colonies do better at subtle distinctions but big swarms may snag the best options.

When house hunting, Temnothorax ants (pictured) recruit each other to potential new homes. Takao Sasaki at Arizona State University in Tempe and his colleagues forced isolated ants and whole colonies to choose between two nest sites. When one site was only slightly better than another, the colonies did better than individuals at picking the best site. When site differences were larger, the ants performed better as individuals.

But big colonies are better when there are more choices to be made. Timothy Schaerf and colleagues at the University of Sydney, Australia, used mathematical models and field experiments to compare how honeybees (Apis mellifera) picked out a new nesting site. Swarms of 15,000 bees chose ideal locations more often than those with 5,000 bees. Huge swarms contain more scouts, and so can collect and compare more options for potential digs.

J. R. Soc. Interface 10, 20130533 (2013); Proc. Natl Acad. Sci. USA http:// dx.doi.org/10.1073/ pnas. 1304917110 (2013)

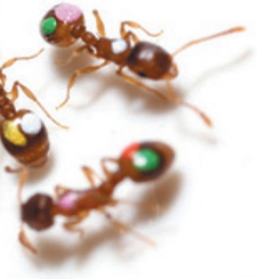

EVOLUTION

\section{Mammals and monogamy}

Some mammals may have turned to pair-living because of infanticide or isolated females.

Using an evolutionary tree of 230 primates as a framework, Christopher Opie of University College London and his colleagues ran simulations of evolutionary history to investigate what conditions might produce the behaviours of modern primates. They conclude that monogamy arose after males began guarding females to stop rivals from killing their offspring.

Tim Clutton-Brock and Dieter Lukas at the University of Cambridge, UK, used a similar method to study how monogamy came about in mammals generally. Using an evolutionary tree of more than 2,000 species, they found that monogamy tended to arise when females lived alone and were widely dispersed. Pair-living probably arose because males could not cover a large enough area to monopolize more than one female.

Proc. Natl Acad. Sci. USA

http://dx.doi.org/10.1073/

pnas.1307903110 (2013);

Science 341, 526-530 (2013)

For a longer story on this research, see go.nature.com/glatpz

\section{MOLECULAR PSYCHIATRY}

\section{A factor for autism and schizophrenia}

Deficits in a protein that binds RNA may be a common risk factor for disorders including schizophrenia, autism and cognitive impairment.

Nelson Freimer at the University of California, Los Angeles, Utz Fischer of the University of Würzburg, Germany, and their colleagues studied a population in northern Finland in which such disorders are particularly frequent. They discovered that many people in this

COMMUNITY CHOICE

The most viewed papers in science

ENVIRONMENTAL SCIENCES

\title{
Ships acidify oceans
}

\section{Highly Read \\ on wiley.com}

Pollution from ships can make the waters of heavily trafficked trade routes more acidic, and may contribute to

local acidification on a scale similar to that resulting from increased atmospheric carbon dioxide.

David Turner at the University of Gothenburg in Sweden and his colleagues modelled the effects of shipping emissions in the world's waters using grids of 1 degree longitude and latitude. This fine detail suggested that ships' emissions of sulphur oxide and nitrogen oxide acidify the water in some busy Northern Hemisphere coastal areas by up to $0.002 \mathrm{pH}$ units each summer. Regulations that allow ships to reduce emissions to the air by 'scrubbing' fuel exhaust with sea water may accelerate acidification by transferring acid to surface waters.

Although not a significant driver of ocean acidification globally, shipping acidification could be a concern where high traffic occurs near fisheries or important regions of marine biodiversity, the authors say.

Geophys. Res. Lett. 40, 2731-2736 (2013)

region are missing a small part of a chromosome that includes the gene for the RNAbinding protein TOP $3 \beta$. The mutation increases the risk of schizophrenia and several other neurodevelopmental disorders.

TOP3 $\beta$ interacts with FMRP, a protein associated with Fragile X syndrome and autism. In a separate paper, Sige Zou and Weidong Wang of the National Institute on Aging in Baltimore, Maryland, and their colleagues characterized these interactions and show that mutations in TOP $3 \beta$ or in FMRP can cause abnormal development of synapses in flies and mice.

Nature Neurosci. http://dx.doi. org/10.1038/nn.3484; http:// dx.doi.org/10.1038/nn.3479 (2013)

\section{PLANT BIOLOGY}

\section{Cheating orchids turn over new leaf}

Many orchids lure pollinators with unfulfilled promises of nectar, but some former deceivers have evolved the ability to produce the sugary reward.

Up to $40 \%$ of orchid species are thought to be floral fibbers, including many members of the diverse Disa genus of African orchids (Disa uniflora pictured). Steven Johnson and his colleagues at the University of KwaZulu-Natal in South Africa analysed 111 Disa species, characterizing each for the presence or absence of nectar.

By mapping these data on to an evolutionary tree of the genus, the researchers showed that nectar production evolved from deceitful ancestors nine times and was lost once. The authors speculate that such transitions may be guided by ecological circumstances that favour the fitness of one system over the other.

Biol. Lett. 9, 20130500 (2013)

\section{NATURE.COM}

For the latest research published by Naturevisit:

www.nature,com/latestresearch 